\title{
Integrating Perioperative Chemotherapy into the Treatment of Muscle-Invasive Bladder Cancer: Strategy Versus Reality
}

\author{
S. Machele Donat, MD, New York, New York
}

\section{Key Words}

Perioperative chemotherapy, muscle invasive, bladder cancer, cystectomy

\begin{abstract}
Since the initial report in 2003 of the Intergroup-0080 trial confirming benefit of combined neoadjuvant M-VAC (methotrexate, vinblastine, adriablastine, and cisplatin) chemotherapy and cystectomy in the treatment of muscle-invasive bladder cancer, debate has continued in the literature as to the relative risk/benefits of integrating perioperative chemotherapy into the care of patients, especially in those with organ-confined, muscle-invasive, node-negative disease in whom the benefit may be less. Because of the inaccuracies of clinical staging, the potential morbidity related to M-VAC chemotherapy, a $70 \%$ cure rate in pT2No disease with surgery alone, and only a modest (5\%) improvement in absolute overall survival with combined therapy, many favor limiting chemotherapy to patients with a pathologic stage of pT3 or greater or node-positive disease. This philosophy was also reflected in the 2008 National Comprehensive Cancer Network Clinical Practice Guidelines in Oncology: Bladder Cancer, in which neoadjuvant chemotherapy for clinical T2 disease versus adjuvant therapy based on pathologic risks is only "considered." Additionally, a recent study looking at the perioperative integration of chemotherapy for stage III bladder cancer in the United States using the National Cancer Data Base showed that only $11.6 \%$ of patients underwent any perioperative chemotherapy, with most in the adjuvant setting. These findings indicate that despite randomized trial data showing survival benefit for perioperative chemotherapy, and the current guidelines for therapy supporting those findings, chemotherapy is not being integrated well into the care of patients with
\end{abstract}

From the Division of Urology, Memorial Sloan-Kettering Cancer Center, New York, New York.

Submitted July 3, 2008; accepted for publication October 14, 2008 The author has no financial interest, arrangement, or affiliation with the manufacturers of any products discussed in the article or their competitors.

Correspondence: S. Machele Donat, MD, Department of Urology, Memorial Sloan-Kettering Cancer Center, Weill Cornell Medical

College, 1275 York Avenue, New York, NY 10065.

E-mail: donats@mskcc.org muscle-invasive bladder cancer, even in those who, experts agree, have the most potential for benefit. (JNCCN 2009;7:40-47)

\section{Rationale for Perioperative Chemotherapy}

Cancer statistics for 2008 estimate bladder cancer will be the fifth most common cancer diagnosed $(68,810$ new cases) in the United States, the eighth most common cause of cancer death in men, and the fourth leading cause of cancer deaths overall in those 80 years of age or older. ${ }^{1}$ Although most patients will have superficial disease at presentation, approximately one third will have muscle-invasive disease, for which radical cystectomy with a bilateral pelvic lymph node dissection is considered the standard surgical treatment..$^{2-6}$ However, with surgery alone, $20 \%$ to $30 \%$ of patients with pT2 disease, $40 \%$ to $60 \%$ with pT 3 disease, and $70 \%$ to $90 \%$ with pT 4 tumors will develop distant metastases or local recurrences and ultimately die of their cancer, indicating the need for the addition of systemic therapy to improve cure rates. ${ }^{7}$ Consequently, 5 -year survival rates after radical cystectomy in contemporary series average $66 \%$ for pT2 disease, $35 \%$ for $\mathrm{pT} 3$ disease, and $27 \%$ for $\mathrm{pT} 4$ disease, ${ }^{7}$ with the poorest survival in those with extravesical or node-positive disease..$^{2-7}$ This may be largely because of the correlation between nodal involvement and increasing bladder stage, with the incidence of positive nodes approximately $10 \%$ in those with superficial muscle invasion (pT2a), 20\% with deep muscle invasion (pT2b), and 40\% with extravesical disease $(\mathrm{pT} 3 / 4))^{2-7}$

The high risk for recurrence and death with cystectomy alone and success with combined therapy in other disease systems, such as breast and colon cancers, has been the rationale for combining perioperative chemotherapy with surgery to target micrometastasis, and thereby improve outcomes. A survival benefit has been shown for patients 
Perioperative Chemotherapy in Muscle-Invasive Bladder Cancer

with overt metastatic disease using combination cisplatin-based chemotherapy. ${ }^{8,9}$ Therefore, it made sense to incorporate therapy when the disease burden may have been lower and the potential benefit greater. Because of the encouraging responses seen in primary tumors in patients with overt metastasis, chemotherapy was evaluated preoperatively in patients undergoing cystectomy, in whom a significant 5 -year survival advantage ( $54 \%$ vs. $12 \%$ ) was noted in those who had been down-staged to less than pT2 disease and served as an impetus for further study. ${ }^{7,10,11}$

\section{Perioperative Chemotherapy Trial Data}

Perioperative chemotherapy has been studied in patients with muscle-invasive bladder cancer undergoing cystectomy in both the neoadjuvant and adjuvant setting; however, interpretation of the results has been problematic because of poor trial design, poor patient accrual, inferior chemotherapy regimens, and poor trial execution in many of the trials. ${ }^{11-18}$ Therefore, meta-analyses of these randomized trials have also been performed to provide stronger evidence to sup- port the role of perioperative chemotherapy in patients with invasive bladder cancer. ${ }^{15-18}$

A recent update of the meta-analyses of 11 randomized control trials (RCTs) involving 3005 patients ( $98 \%$ of patients from all known eligible trials) evaluated the usefulness of neoadjuvant platinum-based combination chemotherapy. This study confirmed a modest survival benefit, with an approximate $5 \%$ absolute improvement in overall survival at 5 years $(P=.003)$ consistent across all patient subgroups, irrespective of the type of local treatment, and a $14 \%$ reduction in the risk for death (Fig. 1). ${ }^{17}$ In addition, the authors found a significant disease-free survival benefit associated with platinum-based combination chemotherapy (hazard ratio [HR], 0.78; 95\% CI, $0.71-0.86 ; P<.0001$ ), equivalent to a $9 \%$ absolute improvement at 5 years.

Evidence supporting adjuvant chemotherapy is less clear because of the small size and limited quality of trial data available, but it seems to be favored by clinicians, most likely because of the ability to make treatment decisions based on pathologic rather than clinical staging. ${ }^{14,18-20}$ A meta-analysis based on 491

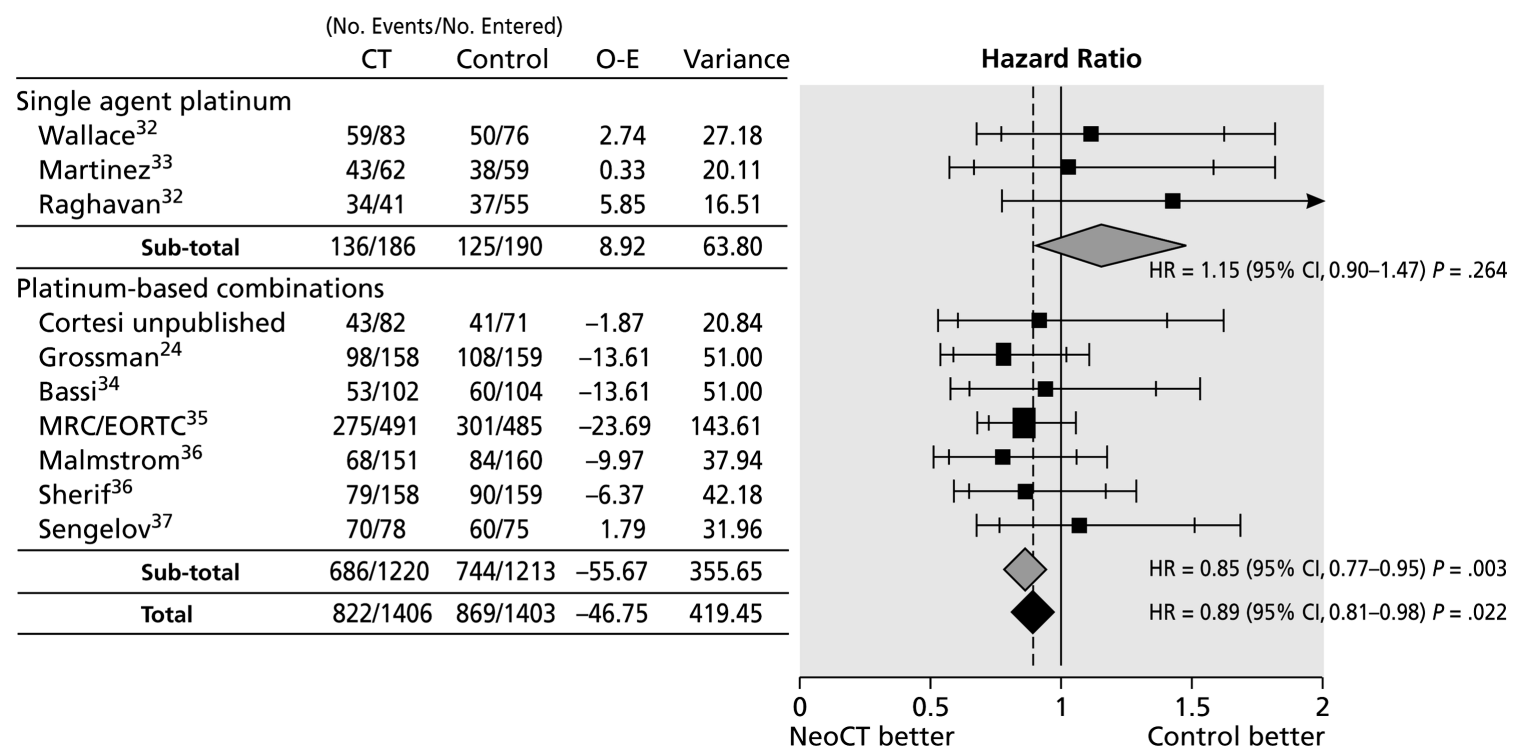

Figure 1 Meta-analyses of randomized controlled trials for neoadjuvant chemotherapy in invasive bladder cancer.

HR plot for overall survival. Each trial is represented by a square, the center of which gives the HR for that trial. Size of the square is proportional to the information in that trial. Ends of horizontal bars denote the $99 \% \mathrm{CI}$ and inner bars mark the $95 \%$ CI. Trials are ordered chronologically by start date (oldest first). The black diamond gives the overall HR for the combined results of all trials; the center denotes the HR, the extremities the $95 \%$ CI. The shaded diamonds denote the HRs for the trial groups; the center denotes the HR, the extremities the $95 \%$ CI. Single-agent platinum: heterogeneity $\mathrm{Chi}^{2}=1.11(P=.57)$; inconsistency $I^{2}=0 \%$. Platinum-based combinations: heterogeneity Chi ${ }^{2}=2.81(P=.83)$; inconsistency $I^{2}=0$. All trials: heterogeneity $\mathrm{Chi}^{2}=8.67(P=.57)$; inconsistency $I^{2}=0$.

Abbreviations: CI, confidence interval; CT, chemotherapy; NeoCT, neoadjuvant chemotherapy; O-E, observed minus expected events; HR, hazard ratio. From Advanced Bladder Cancer (ABC) Meta-analysis Collaboration. Neoadjuvant chemotherapy in invasive bladder cancer: update of a systematic review and meta-analysis of individual patient data. Eur Urol 2005;48:204; with permission. 
Donat

patients from 6 RCTs, representing $90 \%$ of all patients from platinum-based combination chemotherapy trials and $66 \%$ from all eligible trials, reported a $25 \%$ (overall HR, 0.75; 95\% CI, 0.60-0.96; P = .019) relative reduction in the risk of death with chemotherapy equivalent to a $9 \%(95 \% \mathrm{CI}, 1 \%-16 \%)$ absolute improvement in survival at 3 years (Fig. 2). ${ }^{18}$ Again, when considering only cisplatin-based combination chemotherapy trials, the absolute improvement in survival at 3 years increases to $11 \%\left(95 \%\right.$ CI, 3\%-18\%). ${ }^{18}$

Until recently, the influence that quality of surgery may have on the outcomes of perioperative chemotherapy trials was not considered when analyzing trial outcomes or in trial design. Retrospective analyses of single-institution cystectomy series and from the Surveillance, Epidemiology and End Results (SEER) Program cancer registry indicate that overall survival with cystectomy improves as the number of nodes examined increases and that the number of nodes removed can be used as a surrogate measure of the quality of lymphadenectomy. ${ }^{21-23}$ Findings from a recent retrospective subset analysis of the randomized cooperative Intergroup-0080 trial evaluating the influence of surgical factors on outcomes after adjusting for pathologic and chemotherapy treatment factors further supports the importance surgical technique has on outcomes. ${ }^{24,25}$ The authors examined surgical factors, including soft tissue surgical margins, number of nodes removed, and surgeon experience, as well as institution type, accounting for other patient, pathologic, and treatment variables. In a multivariate analysis of surgical predictors for postcystectomy survival that adjusted for other covariates (treatment type, age, pathologic stage, and node status), surgical soft tissue margin status (positive vs. negative; $P=.0007$ ) and number of nodes removed ( $<10$ vs. $>10 ; P=.0001)$ were the strongest independent surgical predictors of local recurrence and overall survival (Table 1).25 Unsurprisingly, soft tissue surgical margin status and the extent of the node dissection as expressed by the number of nodes removed were associated with each other, and a positive surgical margin was associated with fewer nodes removed $\left(P=.01\right.$ from $\chi^{2}$ test $){ }^{25}$ These findings, although not conclusive, suggest that the quality of surgery significantly influences bladder cancer outcomes, and that chemotherapy is unlikely to compensate for poorly performed surgery.

\section{Integration of Perioperative Chemotherapy}

Most clinicians agree that current evidence supports the use of perioperative chemotherapy in patients with muscle-invasive bladder cancer; however, debate

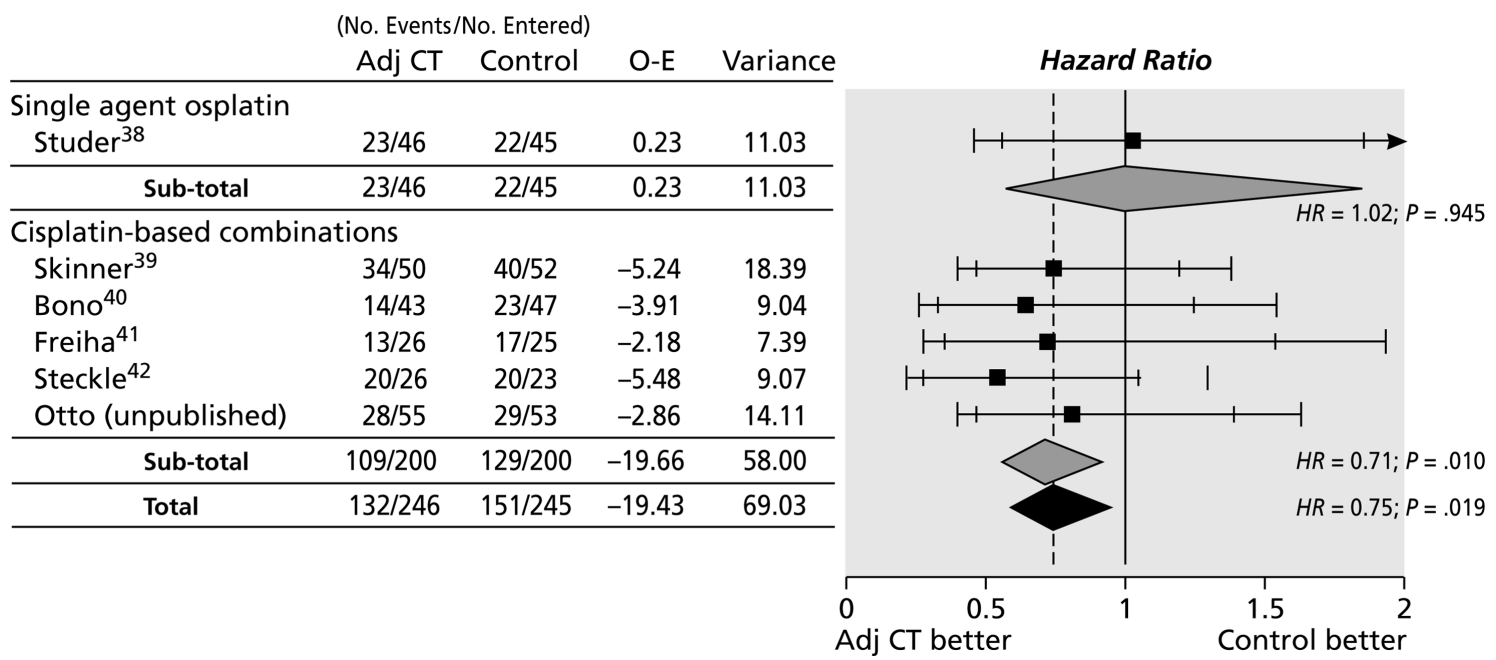

Figure 2 Meta-analyses of randomized controlled trials for adjuvant chemotherapy in invasive bladder cancer.

HR plot for survival. Each individual trial is represented by a square, the center of which denotes HR for the trial; extremities of horizontal bars denote 99\% CI and inner bars mark 95\% CI. Size of square is directly proportional to amount of information in the trial. The black diamond gives the overall HR for combined results of all trials; the center denotes HR, and the extremities the 95\% CI. The shaded diamonds represent HRs for the trial groups; the center denotes the HR, and the extremities the 95\% CI. Trials are ordered chronologically by date of start of trial (oldest first). Abbreviations: Adj CT; adjuvant chemotherapy; CI, confidence interval; O-E, observed minus expected events; HR, hazard ratio. From Advanced Bladder Cancer ( $\mathrm{ABC}$ ) Meta-analysis Collaboration. Adjuvant chemotherapy in invasive bladder cancer: a systematic review and meta-analysis of individual patient data. Eur Urol 2005;48:195; with permission. 
Perioperative Chemotherapy in Muscle-Invasive Bladder Cancer

Table 1 Multivariate Analysis of Surgical Factors Influencing Bladder Cancer Outcomes

\begin{tabular}{|c|c|c|c|c|}
\hline \multirow[b]{2}{*}{ Variables Analyzed } & \multicolumn{2}{|c|}{ Local Recurrence } & \multicolumn{2}{|c|}{ Overall Survival } \\
\hline & $\begin{array}{l}\text { Odds Ratio } \\
(95 \% \mathrm{Cl})\end{array}$ & $P$ Value $^{*}$ & $\begin{array}{l}\text { Hazard Ratio } \\
(95 \% \mathrm{Cl})\end{array}$ & $P$ Value* \\
\hline \multicolumn{5}{|l|}{ Treatment and pathologic factors } \\
\hline Treatment (RC vs. M-VAC + RC) & $0.49(0.18-1.33)$ & .16 & $1.0(0.7-1.4)$ & $.97^{\dagger}$ \\
\hline Pathologic stage (3-4 vs. $0-2$ ) & $3.83(1.20-12.23)$ & .02 & $2.3(1.5-3.6)$ & .002 \\
\hline Node status (positive vs. negative) & $1.68(0.54-5.20)$ & .37 & $1.6(1.0-2.5)$ & .04 \\
\hline \multicolumn{5}{|l|}{ Surgical factors } \\
\hline Surgical margins (positive vs. negative) & $11.17(3.30-37.83)$ & .0001 & $2.7(1.5-4.9)$ & .0007 \\
\hline Number nodes removed (< 10 vs. $\geq 10$ ) & $5.13(1.81-14.71)$ & .002 & $2.0(1.4-2.8)$ & .0001 \\
\hline
\end{tabular}

Each hazard ratio, odds ratio, and $P$ value is adjusted for all other co-variates in the model.

Abbreviations: RC, radical cystectomy, M-VAC, methotrexate, vinblastine, doxorubicin, and cisplatin.

${ }^{*} P$ values are 2 -sided and based on the Wald $\chi^{2}$ test.

${ }^{\dagger}$ Treatment was insignificant because $\mathrm{pT}$ stage explains much of the treatment effect.

Data from Herr HW, Faulkner JR, Grossman HB, et al. Surgical factors influence bladder cancer outcomes: a cooperative group

report. J Clin Oncol 2004;22:2781-2789.

continues over the optimal timing with cystectomy. Tables 2 and 3 summarize the common reasons for using neoadjuvant versus adjuvant therapy and the supporting data for each. Although more supportive data exists for the use of neoadjuvant therapy, a recent study using the National Cancer Data Base indicates that in the United States most perioperative chemotherapy is given in the adjuvant setting. ${ }^{19}$ Proponents for adjuvant therapy argue that neoadjuvant chemotherapy confers risk for disease progression because 1) it delays local therapy (surgery) for the primary tumor, 2) it increases the difficulty of the surgery possibly increasing morbidity, 3) patients may be overtreated unnecessarily (high cure rate for $\leq \mathrm{pT} 2 \mathrm{~N} 0$ disease with surgery alone), 4) the toxicity of the therapy outweighs the benefit, and 5) adjuvant therapy is equally as effective. ${ }^{20,26}$

However, data from neoadjuvant RCTs have not shown a detrimental effect associated with delayed surgery, and comparisons of data on delay in time to treatment of greater than 12 weeks are inappropriate because patients were not undergoing any treatment before surgery in those studies. ${ }^{7,12,14,16,18}$ In a recent study comparing a delay of greater than versus less than 3 months from transurethral resection to cystectomy, Nielsen et al. ${ }^{27}$ were unable to show a significant association among risk for extravesical disease, nodal status, disease recurrence, and overall or diseasespecific survival.

Furthermore, a trial reported by Millikan et al..$^{28}$ randomizing 140 patients to 2 chemotherapy cycles before surgery and 3 after surgery versus 5 cycles after surgery showed that $97 \%$ of patients in the neoadjuvant arm underwent at least 2 cycles of therapy compared with only $77 \%$ of patients in the adjuvant arm. This finding is consistent with reports from other RCTs evaluating adjuvant therapy, indicating that only $50 \%$ to $70 \%$ of patients actually underwent the planned 3 or 4 cycles of adjuvant therapy, compared with $87 \%$ to $97 \%$ in the neoadjuvant setting., ${ }^{7,18}$ In addition, an opposing theoretical argument would be that a delay in initiation of adjuvant therapy carries an equal risk for growth of distant micrometastasis while awaiting the initiation of systemic therapy.

In the trial by Millikan et al., ${ }^{28}$ although the investigators planned to administer adjuvant therapy within 84 days, it was actually initiated within an average of 103 to 114 days because of delays in postoperative recovery. Various reasons have been cited for delaying adjuvant therapy, including delayed recovery from surgery, renal insufficiency, patient refusal, surgical complications, poor performance status, psychological distress, and old age. ${ }^{7}$ A recent retrospective review of Memorial Hospital's surgical experience estimates that up to $30 \%$ of patients undergoing a radical cystectomy may experience a complication within the 90 days during which adjuvant therapy would be started, potentially delaying or preventing its initiation. ${ }^{29}$

Despite speculation that neoadjuvant chemotherapy may increase the difficulty of surgery, and thereby 
Donat

\begin{tabular}{|c|c|c|}
\hline Neoadjuvant Arguments & $\begin{array}{l}\text { Supported } \\
\text { by Data }\end{array}$ & Comments \\
\hline \multicolumn{3}{|l|}{ Pro } \\
\hline Chemotherapy more tolerable before surgery & Yes & $\begin{array}{l}\text { Higher proportion completed } 3 \text { cycles of } \\
\text { therapy in RCTs than adjuvant therapy }\end{array}$ \\
\hline Sooner treatment for micrometastasis & Yes & $\begin{array}{l}10 \%-40 \% \text { will be upstaged with } \\
\text { increasing risk by pathologic stage }\end{array}$ \\
\hline Primary tumor evaluable for response & Yes & $\begin{array}{l}\text { May monitor tumor endoscopically and } \\
\text { radiographically }\end{array}$ \\
\hline Downstaging improves tumor resectability & Yes & $\begin{array}{l}\text { Downstaging to } \leq \mathrm{pT} 2 \mathrm{No} \text { has been } \\
\text { shown to improve overall survival }\end{array}$ \\
\hline $\begin{array}{l}\text { Allows evaluation of molecular markers of } \\
\text { response and chemoresistance }\end{array}$ & Yes & $\begin{array}{l}\text { Pre- and posttreatment tissue available } \\
\text { for study }\end{array}$ \\
\hline Best level 1 evidence supporting use & Yes & RCT data supports \\
\hline \multicolumn{3}{|l|}{ Con } \\
\hline Delay to surgery risks progression of disease & No & Not apparent in neoadjuvant RCT data \\
\hline $\begin{array}{l}5 \% \text { gain in survival not enough to offset } \\
\text { risks associated with chemotherapy }\end{array}$ & $?$ & $\begin{array}{l}\text { Subjective assessment; } 14 \% \text { reduction in } \\
\text { risk for death in meta-analyses; median } \\
\text { survival increased significantly ( } 77 \text { vs. } 46 \text { mo) }\end{array}$ \\
\hline $\begin{array}{l}\text { Chemotherapy increases technical } \\
\text { difficulty of surgery }\end{array}$ & No & $\begin{array}{l}\text { No increased morbidity associated with } \\
\text { postchemotherapy resection in RCTs }\end{array}$ \\
\hline $\begin{array}{l}\text { Unnecessary treatment secondary to } \\
\text { clinical overstaging }\end{array}$ & $?$ & $\begin{array}{l}\text { More likely to be upstaged to } \mathrm{N}+\text { or } \\
\text { pT3 disease; pT2 still experienced } \\
\text { 30-month improvement in survival in } \\
\text { SWOG } 8710 \text { trial }\end{array}$ \\
\hline Toxicity outweighs benefit & $?$ & No deaths in SWOG 8710 trial \\
\hline High cure rate for pT2N0 with surgery alone & Yes & $\begin{array}{l}\text { Median survival still improved by } 30 \text { months } \\
\text { with neoadjuvant chemotherapy; surgery } \\
\text { alone will fail to benefit } 20 \%-30 \% \text { of patients }\end{array}$ \\
\hline
\end{tabular}

Abbreviations: RCTs, randomized control trials; SWOG, Southwest Oncology Group.

surgical morbidity, no significant differences in surgical morbidity were reported in the neoadjuvant RCTs or other trials. ${ }^{14-17,24,28}$ In the Intergroup trial, the planned cystectomy was performed in $82 \%$ of patients in the combined-treatment arm versus $81 \%$ in the surgery-alone arm. ${ }^{24}$ Moreover, significant down-staging of tumors was achieved with an overall pT0 rate of $38 \%$, including $50 \%$ of patients with an initial clinical stage T2 and 30\% of those with an initial clinical stage of T3 or T4a. A similar pT0 rate of 33\% was achieved in the largest single study of neoadjuvant chemotherapy $(\mathrm{N}=976){ }^{11,17,18}$

However, the high cure rates for surgery alone with pT2 disease $(57 \%-79 \%)$ in contemporary surgical series and the inaccuracies of clinical staging have still led many urologists to favor adjuvant therapy in only those considered at high risk for recurrence $(\geq \mathrm{pT} 3$ and/or $\mathrm{N}+$ ) with surgery alone..$^{30}$ On the other hand, a relapse rate of $30 \%$ to $40 \%$ with surgery alone is not insignificant, nor is a potential improvement in median survival of 30 months for those with pT2 disease as seen in the neoadjuvant therapy arm in the Intergroup trial. ${ }^{7,24}$

The high rate of clinical understaging, even in experienced hands, must also be considered..$^{24,30}$ Millikan et al. ${ }^{28}$ reported only a $40 \%$ correlation between clinical and pathologic stage, with $61 \%$ of patients upstaged to $\mathrm{pT} 3$ and/or $\mathrm{N}+$ disease. This occurred despite 2 independent urologists corroborating on the clinical stage.

Lastly, chemotherapy given in the neoadjuvant setting allows assessment of tumor response, which helps determine the effectiveness of chemotherapy, future development of molecular markers predicting 
Perioperative Chemotherapy in Muscle-Invasive Bladder Cancer

\begin{tabular}{|c|c|c|}
\hline Adjuvant Arguments & $\begin{array}{l}\text { Supported } \\
\text { by Data }\end{array}$ & Comments \\
\hline \multicolumn{3}{|l|}{ Pro } \\
\hline Pathologic staging more accurate & Yes & True \\
\hline Avoids delayed treatment for primary tumor & No & $\begin{array}{l}\text { Neoadjuvant RCT data show no detrimental } \\
\text { effect with delay of surgery }\end{array}$ \\
\hline $\begin{array}{l}\text { Avoids therapy in those with less } \\
\text { potential benefit }\end{array}$ & $?$ & $\begin{array}{l}\text { All clinical stages of muscle-invasive disease } \\
\text { showed survival benefit in neoadjuvant RCTs; } \\
\text { no marker lesion to detect chemoresistance, } \\
\text { and therefore some will undergo adjuvant } \\
\text { therapy unnecessarily }\end{array}$ \\
\hline Equally effective as neoadjuvant data & No & $\begin{array}{l}\text { Evidentiary data not as strong as } \\
\text { neoadjuvant therapy }\end{array}$ \\
\hline Minimizes tumor burden to be treated & $?$ & $\begin{array}{l}\text { Theoretical; no data; may decrease primary } \\
\text { tumor volume, but regional and distant disease } \\
\text { may progress secondary to delay of surgery }\end{array}$ \\
\hline \multicolumn{3}{|l|}{ Con } \\
\hline $\begin{array}{l}\text { Postoperative morbidity may delay or } \\
\text { prevent therapy }\end{array}$ & Yes & $\begin{array}{l}\text { Up to } 30 \% \text { may have a surgical complication } \\
\text { that can preclude or delay chemotherapy }\end{array}$ \\
\hline Morbidity rate associated with chemotherapy & Yes & Improved with newer regimens \\
\hline Primary tumor inevaluable for response & Yes & $\begin{array}{l}\text { Unable to detect chemoresistance and } \\
\text { therefore risks unnecessary therapy }\end{array}$ \\
\hline $\begin{array}{l}\text { Does not allow evaluation of molecular } \\
\text { markers of response and chemoresistance }\end{array}$ & Yes & True \\
\hline Evidentiary data less conclusive & Yes & True \\
\hline
\end{tabular}

Abbreviations: $\mathrm{RCT}$, randomized control trial.

response and chemoresistance, and development of new chemotherapeutic agents; and is not possible with adjuvant therapy. Proponents of adjuvant therapy, however, would argue that because of the inaccuracies of clinical staging, some patients will undergo neoadjuvant therapy unnecessarily. Similarly, adjuvant therapy carries the risk for continued treatment with an ineffective regimen because no marker lesion is present to assess for response, whereas neoadjuvant therapy allows for an interim assessment of response and a change in therapy, or earlier surgical intervention if the tumor is chemoresistant.

\section{Conclusion: Strategy Versus Reality}

The reality today is that perioperative chemotherapy, and particularly neoadjuvant therapy, is substantially underused despite evidence showing a survival benefit, indicating that the strategy has not been well implemented. ${ }^{7,19,30}$ The best evidentiary data support chemotherapy in the neoadjuvant setting for muscle- invasive disease. ${ }^{711-17}$ Experts also know that patients are more likely to undergo at least 3 cycles (therapeutic) of therapy when given in the neoadjuvant setting compared with the adjuvant setting. ${ }^{7,28}$ However, although most would agree that patients at the highest risk for recurrence (e.g., those with pT3 and/or $\mathrm{N}+$ disease) should undergo perioperative chemotherapy, a recent review of the National Cancer Data Base evaluating the strategy of perioperative chemotherapy in patients with stage III bladder cancer showed that only $11.6 \%$ underwent any perioperative chemotherapy, and most in the adjuvant setting. ${ }^{19}$

Furthermore, an analysis of the patterns of care and outcomes for muscle-invasive bladder cancer in the Medicare population using the SEER program data indicates that surgical standards are not being met either. Only 39\% of patients with muscle-invasive disease underwent radical cystectomy within 6 months of diagnosis, most either without node dissections or with inadequate dissections, which clearly impacts 
Donat

survival. ${ }^{23,25,31}$ Although patient comorbidities may account for some underuse of chemotherapy and cystectomy, it is unlikely they would result in $88 \%$ of patients with stage III bladder cancer failing to undergo perioperative chemotherapy and only $39 \%$ of patients undergoing cystectomy as definitive treatment. ${ }^{19,23,31} \mathrm{~A}$ better understanding is needed of why chemotherapy and cystectomy are underused in the treatment of invasive bladder cancer (i.e., patient or physician preferences, referral patterns, access to care, comorbidities, fund of knowledge). In the interim, using neoadjuvant therapy to treat those with invasive bladder cancer $(\geq$ cT2) would make more sense to allow study of gene expression profiles for chemoresistance and response to expedite individualized risk-adjusted therapy for all patients.

\section{References}

1. Jemal A, Siegel R, Ward E, et al. Cancer statistics, 2008. CA Cancer J Clin 2008:58:71-96.

2. Stein JP, Lieskovsky G, Cote R, et al. Radical cystectomy in the treatment of invasive bladder cancer: long-term results in 1,054 patients. J Clin Oncol 2001;19:666-675.

3. Dalbagni G, Genega E, Hashibe M, et al. Cystectomy for bladder cancer: a contemporary series. J Urol 2001;165:1111-1116.

4. Bassi P, Ferrante GD, Piazza N, et al. Prognostic factors of outcome after radical cystectomy for bladder cancer: a retrospective study of a homogeneous patient cohort. J Urol 1999;161:1494-1497.

5. Ghoneim MA, el-Mekresh MM, el-Baz MA, et al. Radical cystectomy for carcinoma of the bladder: critical evaluation of the results in 1,026 cases. J Urol 1997;158:393-399.

6. Knap MM, Lundbeck F, Overgaard J. Prognostic factors, pattern of recurrence and survival in danish bladder cancer cohort treated with radical cystectomy. Acta Oncologica 2003;42:160-168.

7. Herr HW, Dotan Z, Donat SM, Bajorin DF. Defining optimal therapy for muscle invasive bladder cancer. J Urol 2007;177:437-443.

8. Sternberg CN, Yagoda A, Scher HI, et al. Preliminary results of M-VAC for transitional cell carcinoma of the urothelium. J Urol 1985;133:403-404.

9. von der Maase H, Sengelov L, Roberts JT, et al. Long-term survival results of a randomized trial comparing gemcitabine plus cisplatin, with methotrexate, vinblastine, doxorubicin, plus cisplatin in patients with bladder cancer. J Clin Oncol 2005;23:4602-4608.

10. Schultz PK, Herr HW, Zhang ZF, et al. Neoadjuvant chemotherapy for invasive bladder cancer: prognostic factors for survival of patients treated with M-VAC with 5-year follow-up. J Clin Oncol 1994; 12:1394-1401.

11. Sonpavde G, Petrylak DP. Perioperative chemotherapy for bladder cancer. Crit Rev Oncol Hematol 2006;57:133-144.

12. Izawa JI, Chin JL, Winquist E. Timing cystectomy and perioperative chemotherapy in the treatment of muscle invasive bladder cancer. Can J Urol 2006;13:48-53.

13. Dreicer R. Chemotherapy for muscle-invasive bladder cancer in the perioperative setting: current standards. Urol Oncol 2007;25:7275.
14. Pectasides D, Pectasides M, Nikolaou M. Adjuvant and neoadjuvant chemotherapy in muscle invasive bladder cancer: literature review. Euro Urol 2005;48:60-68.

15. Advanced Bladder Cancer Meta-analysis Collaboration. Neoadjuvant chemotherapy in invasive bladder cancer: a systematic review and meta-analysis. Lancet 2003; 7:1927-1934.

16. Winquist E, Kirchner TS, Segal R, et al. Neoadjuvant chemotherapy for transitional cell carcinoma of the bladder: a systematic review and meta-analysis. J Urol 2004;171:561-569.

17. Advanced Bladder Cancer Meta-analysis Collaboration. Neoadjuvant chemotherapy in invasive bladder cancer: update of a systematic review and meta-analysis of individual patient data advanced bladder cancer (ABC) meta-analysis collaboration. Eur Urol 2005;48:202-206.

18. Advanced Bladder Cancer Meta-analysis Collaboration. Adjuvant chemotherapy in invasive bladder cancer: a systematic review and meta-analysis of individual patient data. Eur Urol 2005;48:189-201.

19. David KA, Milowsky MI, Ritchey J, et al. Low incidence of perioperative chemotherapy for stage III bladder cancer 1998 to 2003: a report from the national cancer data base. J Urol 2007;178:451-454.

20. Lehmann N, Retz M, Stockle M. Chemotherapy in the post-MVAC era: the case for adjuvant chemotherapy. World J Urol 2002;20:144-150.

21. Leissner J, Hohenfellner R, Thuroff JW, et al. Lymphadenectomy in patients with transitional cell carcinoma of the bladder: significance for staging and prognosis. BJU Int 2000;85:817-821.

22. Herr HW, Bochner BH, Dalbagni G, et al. Impact of the number of lymph nodes retrieved on outcome in patients with muscle invasive bladder cancer. J Urol 2002;167:1295-1298.

23. Konety BR, Joslyn SA, O'Donnell MA. Extent of pelvic lymphadenectomy and its impact on outcome in patients diagnosed with bladder cancer: analysis of data from the surveillance, epidemiology and end results program data base. J Urol 2003;169:946-950.

24. Grossman HB, Natale RB, Tangen CM, et al. Neoadjuvant chemotherapy plus cytstectomy compared with cystectomy alone for locally advanced bladder cancer. N Engl J Med 2003;349:859-866.

25. Herr HW, Faulkner JR, Grossman HB, et al. Surgical factors influence bladder cancer outcomes: a cooperative group report. J Clin Oncol 2004;22:2781-2789.

26. Raghavan D, Quinn D, Skinner DG, Stein JP. Surgery and adjunctive chemotherapy for invasive bladder cancer. Surg Oncol 2002; 11:55-63.

27. Nielsen ME, Palapattu GS, Karakiewicz PI, et al. A delay in radical cystectomy of $>3$ months is not associated with a worse clinical outcome. BJU Int 2008;100:1015-1020.

28. Millikan R, Dinney C, Swanson D, et al. Integrated therapy for locally advanced bladder cancer: final report of a randomized trial of cystectomy plus adjuvant $\mathrm{M}-\mathrm{VAC}$ versus cystectomy wtih both preoperative and postoperative M-VAC. J Clin Oncol 2001;19:4005-4013.

29. Donat SM, Shabsigh A, Savage C, et al. Potential impact of postoperative complications on the timing of adjuvant chemotherapy in patients undergoing radical cystectomy: a high volume tertiary cancer center experience. Eur Urol 2008, in press.

30. Rosenberg JE. Current status of neoadjuvant and adjuvant chemotherapy for muscle-invasive bladder cancer. Expert Rev Anticancer Ther 2007;7:1729-1736.

31. Schrag D, Mitra N, Xu F, et al. Cystectomy for muscle invasive bladder cancer: patterns and outcomes of care in the Medicare population. Urology 2005;65:1118-1125.

32. Wallace DM, Raghavan D, Kelly KA, et al. Neo-adjuvant (pre-emptive) cisplatin therapy in invasive transitional cell carcinoma of the bladder. Br J Urol 1991;67:608-615. 
Perioperative Chemotherapy in Muscle-Invasive Bladder Cancer

33. Martinez-Piñeiro JA, Gonzalez Martin M, Arocena F, et al. Neoadjuvant cisplatin chemotherapy before radical cystectomy in invasive transitional cell carcinoma of the bladder: a prospective randomized phase III study. J Urol 1995;153:964-973.

34. Bassi PF, Pappagallo GL, Sperandio P, et al. Neoadjuvant MVAC chemotherapy of invasive bladder cancer: results of a multicenter phase III trial. J Urol 1999;161:264.

35. Neoadjuvant cisplatin, methotrexate, and vinblastine chemotherapy for muscle-invasive bladder cancer: a randomised controlled trial. International collaboration of trialists. Lancet 1999;354:533-540. Erratum in: Lancet 1999;354:1650.

36. Sherif A, Holmberg L, Rintala E, et al. Neoadjuvant cisplatinum based combination chemotherapy in patients with invasive bladder cancer: a combined analysis of two Nordic studies. Eur Urol 2004; 45:297-303.

37. Sengel $\varnothing v \mathrm{~L}$, von der Maase $H$, Lundbeck F, et al. Neoadjuvant chemotherapy with cisplatin and methotrexate in patients with muscleinvasive bladder tumours. Acta Oncol 2002;41:447-456.
38. Studer UE, Bacchi M, Biedermann C, et al. Adjuvant cisplatin chemotherapy following cystectomy for bladder cancer: results of a prospective randomized trial. J Urol 1994;152:81-84.

39. Skinner DG, Daniels JR, Russell CA, et al. Adjuvant chemotherapy following cystectomy benefits patients with deeply invasive bladder cancer. Semin Urol 1990;8:279-284.

40. Bono AV, Benvenuti C, Gibba A, et al. Adjuvant chemotherapy in locally advanced bladder cancer. Final analysis of a controlled multicentre study. Acta Urol Ital 1197;11:5-5.

41. Freiha F, Reese J, Torti FM. A randomized trial of radical cystectomy versus radical cystectomy plus cisplatin, vinblastine and methotrexate chemotherapy for muscle invasive bladder cancer. J Urol 1996; 155:495-499.

42. Stöckle M, Meyenburg W, Wellek S, et al. Adjuvant polychemotherapy of nonorgan-confined bladder cancer after radical cystectomy revisited: long-term results of a controlled prospective study and further clinical experience. J Urol 1995;153:47-52. 